\title{
The Women Who Win
}

\author{
Women who have received major physics prizes share their thoughts \\ about what the awards mean to them and about how they help in bringing \\ science to the forefront.
}

By Rachel Berkowitz

$\square$ uring her high school years, Andrea Ghez read biographies of Marie Curie. The books were given to her by her parents, who, she says, understood her interest in science and wanted to instill in her the belief that she could be anything that she wanted. Ghez, an astrophysicist at the University of California, Los Angeles, says it never crossed her mind that she would one day receive the same honor as Curie, a

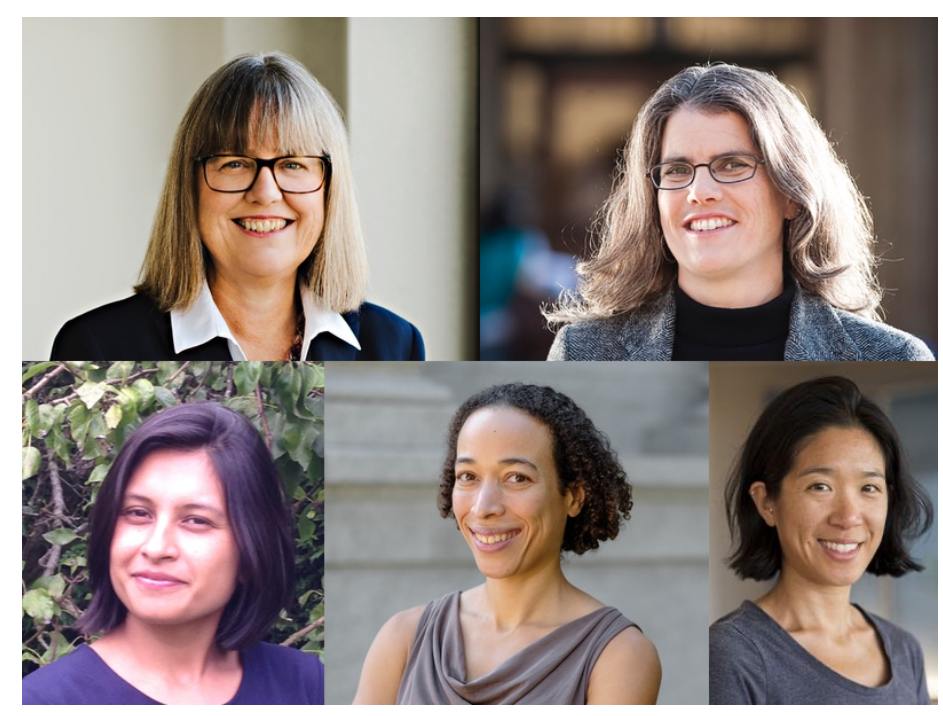

Clockwise from top left: Donna Strickland (Nobel Prize in Physics, 2018), Andrea Ghez (Nobel Prize in Physics, 2020), Tien-Tien Yu (New Horizons in Physics Prize, 2021), Monika Schleier-Smith (MacArthur Fellowship, 2020), and Samaya Nissanke (New Horizons in Physics Prize, 2020) are among the handful of women physicists who have been awarded major prizes for their research. Credit: University of Waterloo, C. Dibble/UCLA, University of Oregon, John D. \& Catherine T. MacArthur Foundation, S. Nissanke
1903 Nobel Prize in Physics awardee.

Although women through history have won major physics prizes, they have received those honors rarely. For example, Curie was the only woman to be awarded the Nobel Prize in Physics for 60 years. As of today, there are four women Nobel physics laureates, including Donna Strickland, who received the prize in 2018, and Ghez, who received it last year (there are 215 Nobel physics laureates in total).

Women physicists are also increasingly receiving other major prizes, which is "heartening, but only a first step," says Samaya Nissanke, an astrophysicist at the University of Amsterdam. Nissanke, who shares her award with Jo Dunkley of Princeton University, was the seventh woman to receive the New Horizons in Physics prize (there have been 62 recipients since its founding in 2013). The community still has work to do to ensure an inclusive, productive, and scientifically enjoyable environment for underrepresented groups, she adds.

In a world where science is increasingly collaborative and competition for opportunities is fierce, what perspective can young scientists gain from these winners' experiences? To find out, Physics interviewed five women who have won big awards to learn about how winning the prize has impacted them and to find out what role they think that these prizes have in today's research environment. In addition to Ghez and Nissanke, the interviewed physicists are Tien-Tien $\mathbf{Y u}$, a dark matter physicist at the University of Oregon who won the 2021 New Horizons in Physics; Donna Strickland, an optical physicist at the University of Waterloo who received a Nobel Prize in Physics in 2018; and Monika Schleier-Smith, a quantum physicist at Stanford University who was awarded a MacArthur Fellowship 
award in 2020.

All interviews are edited for brevity and clarity.

\section{What made you want to become a scientist?}

As a child, Yu says that she wanted to study marine biology. But attending an astrophysics course during her high school senior year led her to make a surprising connection. "The ocean is this wondrous, ethereal world that is very close to us and yet very mysterious," she says. "I realized that the same is true for our Galaxy."

Ghez says that watching the first moon landing, which happened when she was four years old, captured her interest in physics and gave her a sense of the enormity of space, time, and the Universe. That, and an enjoyment of solving puzzles. "My love of physics comes from a passion for problem solving," she says. Meanwhile, an introduction to our Solar System at five years old endowed Nissanke with "a fascination and wonder at the cosmos that continued throughout my childhood, teenage years, and today," she says.

University was where Schleier-Smith and Strickland both developed a passion for physics. Schleier-Smith took a physics course in quantum mechanics and loved it so much that she decided "to pursue a Ph.D. in a field where I'd deal directly with quantum phenomena in the lab." Strickland read a catalog in a high school guidance counselor's office that showed her that a degree in engineering could combine her skills in math and physics with her budding interest in lasers. "Now you see lasers everywhere. Back then, of course, you never saw them," she says.

\section{Did you ever think you might win a major physics prize?}

Ghez, Nissanke, Schleier-Smith, Strickland, and Yu all say that winning came as a complete surprise. "I thought the lab was on fire when the phone rang in the middle of the night. Then I realized Sweden was calling," Strickland says. The winners all also say that they feel that winning their respective prizes conferred on them an opportunity to effect change.

\section{What role do you think awards, such as the Nobel Prize, play in today's research environment?}

Ghez says that winning the Nobel Prize gave her a sense of

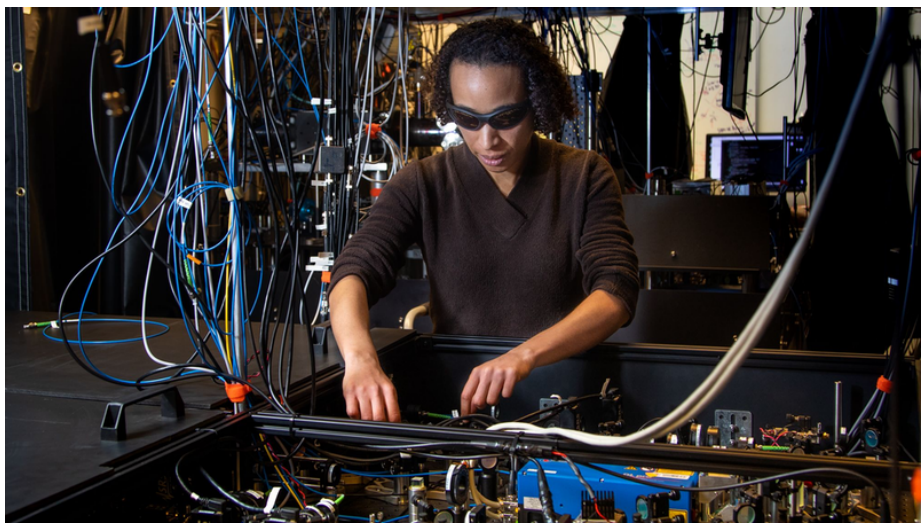

Monika Schleier-Smith works on a cold-atom experiment in her optics lab.

Credit: D. Harmer/Stanford University

responsibility to act as a spokesperson for science. "We live in an interesting moment where science is increasingly under attack," and pushback against that attack is more important than ever, she says. She adds that winning also provides her with an opportunity to express gratitude for the support provided by colleagues and mentors and to highlight what it takes for frontier science research to thrive-something she thinks is often hidden to those outside of academia.

That sentiment is echoed by Strickland, who says that the awards bring science to the attention of the wider public through media coverage of the prizes.

\section{How have you leveraged your prize for advocacy?}

Since winning the Nobel Prize in Physics, Strickland says that she feels that more people in her community pay attention to her voice. Also, she now has seats on various government-led research organizations in Canada and the US, which she never had before.

The award has opened up opportunities for conveying to nonscientists what scientists do and why, something "I embrace," Schleier-Smith says. These opportunities range from interviewing with National Public Radio to sitting on a career panel for high school students. "I love the fact that the MacArthur has led to invitations to speak to so many different audiences."

“I've always believed tremendously in the value of visible role 


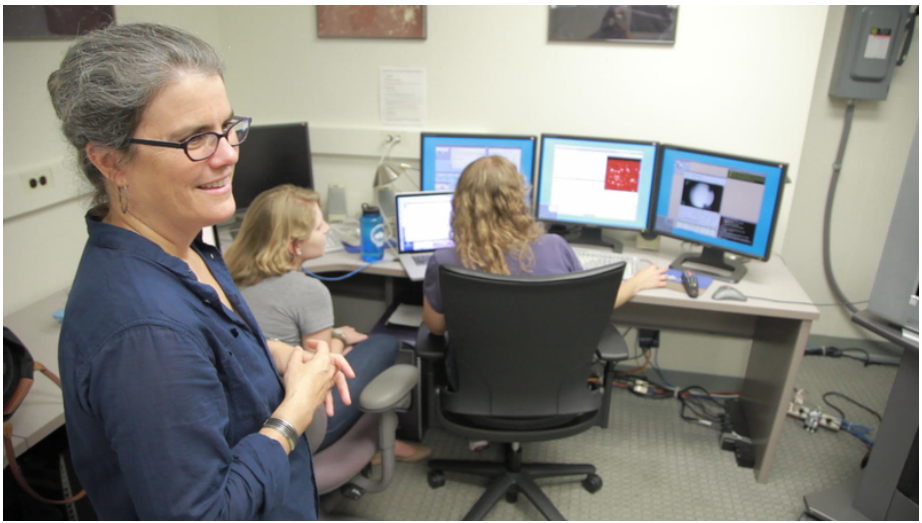

Andrea Ghez and her students analyze data from the Keck Observatory.

Credit: UCLA Galactic Center Group

models," Ghez says. Ghez makes herself visible by teaching introductory undergraduate classes, where, she says, she can shape the next generation's ideas about who can be a scientist.

"As a woman of color, I have faced a myriad of challenges within and outside of science," Nissanke says, adding that she uses the attention garnered from her prize to advocate for diversity in science. She says that, with more role models speaking up about racism and sexism in science and then promoting change from within, she hopes that people from all backgrounds-and not just privileged ones-will consider careers in physics or astronomy. "The night skies are for everyone," she says.

\section{Do prizes like these represent the full scale of science and scientists?}

No, Yu says, and it's partly by construction. "Certain topics are less 'flashy' and hence don't receive the same kind of attention and recognition." Nissanke agrees, adding that current academic structures and metrics of success also limit who is eligible for prizes. "The playing field is very uneven," she says.

While physics and astronomy move toward large experiments and collaboration, the concept of individual contribution also needs revisiting, Nissanke says. Schleier-Smith agrees, pointing out that for small-scale experiments, such as the ones she does with cold atoms, it is generally clear who did what. But for large experiments at big facilities, where thousands of people work together on the same problem, it's harder to define each person's contribution.

\section{What's your top piece of advice for women who want to carve out a path in physics?}

Build a network of friends, colleagues, and mentors, Yu says. That "makes doing physics a joy and makes it easier to weather setbacks and frustrations."

You must really like physics, Strickland says. Similarly, Nissanke says to "keep your love of physics and science personal and pure."

"Follow your passion," Ghez says. Like any pursuit, science poses challenges, she adds. "Being passionate allows you to overcome the inevitable obstacles."

Rachel Berkowitz is a Corresponding Editor for Physics based in Vancouver, Canada. 